\title{
INFLUÊNCIA DOS PARÂMETROS DE TÊMPERA E REVENIMENTO SOBRE A DUREZA E A MICROESTRUTURA DO AÇO AISI M2*
}

\author{
Júnia Bicalho Duarte Rosa' \\ Pedro Penna Coelho Lourenço² \\ Elaine Carballo Siqueira Corrêa ${ }^{3}$ \\ Aline Silva Magalhães ${ }^{4}$ \\ Wellington Lopes ${ }^{5}$ \\ Cíntia Braga ${ }^{6}$
}

\section{Resumo}

Os aços rápidos são aços ferramentas de alta liga capazes de usinar metais a altas velocidades. Dentre estes, o aço rápido AISI M2 é um dos mais empregados, em função das boas propriedades alcançadas mediante a combinação de composição química e parâmetros de tratamentos térmicos. Neste contexto, o objetivo deste trabalho foi avaliar os efeitos da temperatura de aquecimento na têmpera sobre a microestrutura e dureza do aço AISI M2 após revenimento em diversas temperaturas. Para tal, duas temperaturas de têmpera e cinco temperaturas de revenimento foram definidas. As transformações microestruturais foram analisadas por meio de microscopia eletrônica de varredura e difratometria de raios- $X$. A dureza foi obtida por ensaios Rockwell C. Foi observado que, de modo geral, o aumento da temperatura de aquecimento promoveu elevação nos valores de dureza do aço, sendo que, para a maior temperatura utilizada, notou-se a ocorrência do fenômeno de endurecimento secundário. As análises microestruturais revelaram a presença de maior quantidade de carbonetos nas amostras temperadas à menor temperatura.

Palavras-chave: Aço rápido; Tratamento térmico; Endurecimento secundário.

\section{INFLUENCE OF QUENCHING AND TEMPERING PARAMETERS ON THE HARDNESS AND MICROSTRUCTURE OF AISI M2 STEEL}

\section{Abstract}

High speed steels are tool steels capable of machining metals at high speeds. Among these, the AISI M2 high speed steel is one of the most used, due to the good properties achieved through the combination of chemical composition and heat treatments parameters. The aim of this work was to evaluate the effects of quench heating temperature on the microstructure and hardness of AISI M2 steel after tempering at various temperatures. For this, two quenching temperatures and five tempering temperatures were defined. The microstructural transformations were analyzed by means of scanning electron microscopy and X-ray diffraction. The hardness was obtained by Rockwell $C$ tests. It was observed that, in general, the increase of the heating temperature promoted an increase in the hardness values of the steel, being that, for the higher temperature used, it was noted the occurrence of the secondary hardening phenomenon. The microstructural analysis revealed the presence of a higher amount of carbides in the quenched samples at the lower temperature.

Keywords: High speed steel; Heat treatment; Secondary hardening.

Eng. Materiais, Mestranda Eng. Materiais, CEFET-MG, Belo Horizonte, MG, Brasil.

Graduando Eng. de Materiais, CEFET-MG, Belo Horizonte, MG.

Eng. Mecânica, Dra., Profä., Depto. Eng Materiais, CEFET-MG, Belo Horizonte, MG, Brasil.

Eng. Materiais, Mestre, Prof ${ }^{a}$., Depto. Eng. Materiais, CEFET-MG, Belo Horizonte, MG, Brasil.

Eng. Mecânico, Dr., Prof., Depto. Eng Materiais, CEFET-MG, Belo Horizonte, MG, Brasil.

Eng. Materiais, Mestranda Eng. Materiais, CEFET-MG, Belo Horizonte, MG, Brasil. 


\section{INTRODUÇÃO}

Os aços rápidos são os principais tipos de aços ferramenta utilizados quando se deseja cortes a altas velocidades e pesados avanços. Isso se explica por características como alta dureza no estado temperado e retenção da dureza a quente, sendo esta segunda a mais importante propriedade deste tipo de material $[1,2]$. Outras características importantes são a boa resistência ao desgaste e abrasão, estabilidade dimensional e boa tenacidade, o que os permite manter um bom gume cortante por longos períodos [2,3].

As propriedades mencionadas são obtidas pela combinação de composição química e tratamentos térmicos [3]. As composições químicas destes aços variam em amplas faixas e podem atingir níveis elevados de molibdênio, vanádio, tungstênio e cobalto, todos considerados formadores de carbonetos [2,4]. Os efeitos destes elementos em aços especiais alteram tanto as fases ou constituintes presentes em equilíbrio, como a maneira e velocidade com que essas fases se formam [2]. Desse modo, a microestrutura de aços rápidos, na condição temperada, consiste de uma matriz martensítica, austenita retida e elevada concentração de carbonetos heterogeneamente distribuídos. Esses carbonetos são formados durante a solidificação ou o processamento térmico e podem apresentar durezas muito superiores à da martensita e da cementita. No aço rápido ao molibdênio AISI M2, verifica-se a formação dos carbonetos eutéticos: $M_{2} C, M_{6} C, M C$, em que $M$ são os metais presentes no aço, incluindo $\mathrm{W}, \mathrm{Mo}, \mathrm{V}$ e $\mathrm{Cr}$. O tipo predominante de carboneto encontrado nesse aço é o $\mathrm{M}_{2} \mathrm{C}$. A participação desses carbonetos na composição final depende da composição química de base e da taxa de solidificação [5-7].

A estrutura final dos aços rápidos é obtida pelo tratamento térmico de têmpera e revenimento [8]. O revenimento, em especial, é capaz de produzir um fenômeno típico de aços altamente ligados e mais acentuado nos aços rápidos: o endurecimento secundário [1]. O endurecimento secundário, responsável pela elevada dureza a quente de aços rápidos, é resultado da transformação da martensita obtida na têmpera em martensita revenida de alta temperatura; da austenita retida em martensita, durante o resfriamento no revenimento; e, principalmente, da intensa precipitação de carbonetos de elementos de liga finamente dispersos na estrutura [9].

Neste contexto, o objetivo deste trabalho foi avaliar o efeito da temperatura de aquecimento na têmpera sobre a dureza e a microestrutura do aço rápido AISI M2, após revenimento em temperaturas diversas.

\section{MATERIAIS E MÉTODOS}

O material estudado neste trabalho foi o aço rápido AISI M2. Amostras deste aço foram adquiridas comercialmente e a composição química informada pelo fornecedor é mostrada na Tabela 1.

Tabela 1. Composição química informada pelo fornecedor do aço AISI M2

\begin{tabular}{ccccc}
\hline $\mathbf{C}$ & $\mathbf{C r}$ & Mo & $\mathbf{V}$ & $\mathbf{W}$ \\
\hline $0,9 \%$ & $4,1 \%$ & $5,0 \%$ & $1,9 \%$ & $6,4 \%$ \\
\hline Fonte: Schomolz & Bickenback [10]. & & &
\end{tabular}

As condições de têmpera e revenimento foram definidas por meio de consulta à literatura e de acordo com as transformações microestruturais esperadas [11]. Considerando a têmpera, conduzida em um forno da marca Magnus, inicialmente, 
corpos de prova foram aquecidos a $1000^{\circ} \mathrm{C}$, enquanto outros corpos de prova foram aquecidos a $1200^{\circ} \mathrm{C}$. O tempo de encharque foi de uma hora e o meio de resfriamento utilizado foi o óleo. Já os parâmetros de revenimento, realizado em um forno Brasimet, estão mostrados na Tabela 2.

Tabela 2. Parâmetros dos revenimentos empregados

\begin{tabular}{|c|c|c|c|c|}
\hline Amostras & $\begin{array}{c}\text { Temperatura de } \\
\text { revenimento }\end{array}$ & $\begin{array}{c}\text { Tempo de } \\
\text { revenimento }\end{array}$ & $\begin{array}{c}\text { Meio de } \\
\text { resfriamento }\end{array}$ & $\begin{array}{c}\text { Número de } \\
\text { Amostras }\end{array}$ \\
\hline \multirow{6}{*}{$\begin{array}{l}\text { Temperadas } \\
\text { a } 1000^{\circ} \mathrm{C}\end{array}$} & S/ Revenimento & \multirow{6}{*}{1 hora } & \multirow[t]{6}{*}{ 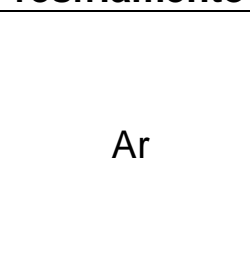 } & 2 \\
\hline & $500^{\circ} \mathrm{C}$ & & & 2 \\
\hline & $525 \stackrel{\circ}{C}$ & & & 2 \\
\hline & $550^{\circ} \mathrm{C}$ & & & 2 \\
\hline & $575 \stackrel{\circ}{ } \mathrm{C}$ & & & 2 \\
\hline & $600^{\circ} \mathrm{C}$ & & & 2 \\
\hline \multirow{6}{*}{$\begin{array}{l}\text { Temperadas } \\
\text { a } 1200^{\circ} \mathrm{C}\end{array}$} & S/ Revenimento & \multirow{6}{*}{1 hora } & \multirow{6}{*}{$\mathrm{Ar}$} & 2 \\
\hline & $500^{\circ} \mathrm{C}$ & & & 2 \\
\hline & $525^{\circ} \mathrm{C}$ & & & 2 \\
\hline & $550^{\circ} \mathrm{C}$ & & & 2 \\
\hline & $575 \stackrel{\circ}{C}$ & & & 2 \\
\hline & $600^{\circ} \mathrm{C}$ & & & 2 \\
\hline
\end{tabular}

Após a realização dos tratamentos térmicos todos os corpos de prova foram seccionados na seção transversal e tanto os ensaios de dureza como análise microestrutural foram realizados na parte interna das amostras, eliminando-se, assim, o eventual efeito da descarbonetação.

As análises de dureza foram realizadas após cada condição de tratamento térmico, por meio de ensaios de dureza Rockwell C, utilizando-se o durômetro da marca IGV, modelo RM401/A. Duas amostras de cada condição foram analisadas e cinco medidas de dureza foram feitas para cada, para que, posteriormente, fosse possível determinar um valor de dureza média. Nota-se, então, que a média foi definida pelos dez valores obtidos para cada condição.

A caracterização microestrutural dos corpos de prova foi realizada por meio de microscopia eletrônica de varredura (MEV). A preparação metalográfica das amostras foi feita em duas amostras de cada condição por embutimento a frio, lixamento, polimento com pasta de diamante e ataque químico com reagente Nital $5 \%$. A microscopia eletrônica de varredura foi realizada em um microscópio da marca Shimadzu, modelo SSX-550.

Para a determinação qualitativa das fases presentes nos corpos de prova após tratamento térmico, utilizou-se a técnica de difração de raios x (DRX). Uma amostra de cada condição foi submetida ao ensaio, realizado em difratômetro da marca Shimadzu, modelo XDR-7000, com ângulo de varredura entre $10^{\circ}$ e $100^{\circ}$ e passo de $0,02 \mathrm{~s}^{-1}$. Antes dos ensaios, as amostras foram submetidas a decapagem em $\mathrm{HCl}$, sendo esse procedimento realizado para remover os efeitos da etapa de preparação nos resultados.

\section{RESULTADOS E DISCUSSÃO}

Os resultados dos ensaios de dureza Rockwell C para as doze condições de tratamentos térmicos empregados estão mostradas na Figura 1. Considerando-se apenas os materiais temperados, sem revenimento, os valores de dureza encontrados são compatíveis com o comportamento esperado para uma 
microestrutura martensítica característica de aço com alto teor de carbono após tratamento térmico. Para o aço temperado a $1000^{\circ} \mathrm{C}$ e revenido, nota-se que independente da temperatura de revenimento a dureza permanece sem alterações significativas.

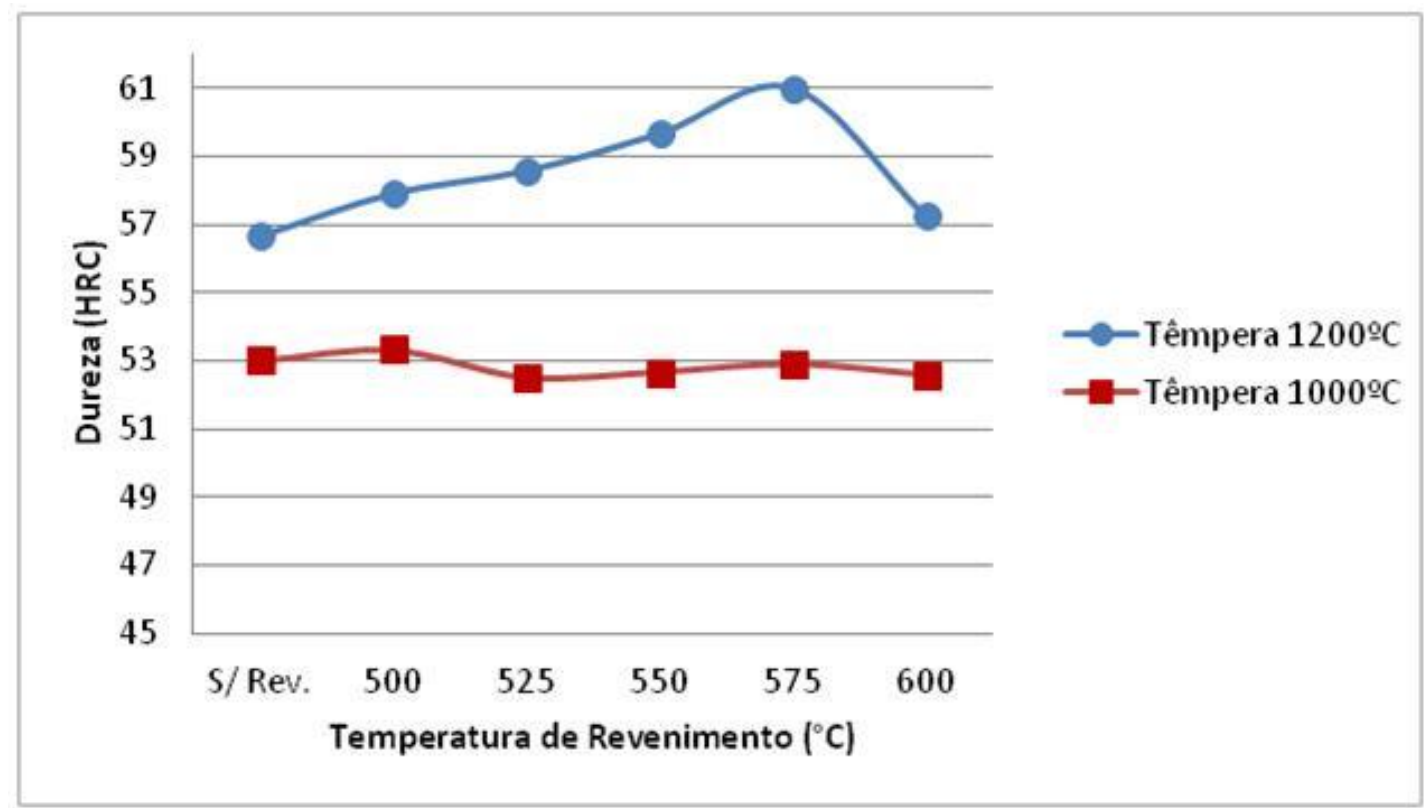

Figura 1. Curvas de dureza para o aço AISI M2 temperado a $1000^{\circ} \mathrm{C}$ e $1200^{\circ} \mathrm{C}$ e revenido a diversas temperaturas.

Esse comportamento possivelmente está associado ao fato de que à temperatura de $1000^{\circ} \mathrm{C}$ de aquecimento na têmpera, o carbono e os elementos de liga que antes estavam na forma de carbonetos não entraram em solução sólida na estrutura austenítica (ou apenas uma reduzida quantidade entrou), a partir da qual formou-se martensita e austenita retida. Logo, durante o revenimento, a quantidade de carbono e elementos de liga em solução na estrutura martensítica foi insuficiente para que a precipitação destes na forma de carbonetos causasse elevação de dureza do material. No entanto, não foi verificada redução progressiva na dureza durante o revenimento, corroborando a informação de que certos elementos de liga retardam a ocorrência de algumas transformações nesse tratamento e, com isso, impedem a queda acentuada da dureza na liga $[1,3]$.

As amostras temperadas a $1200^{\circ} \mathrm{C}$ apresentam valores de dureza superiores aos das amostras temperadas a $1000^{\circ} \mathrm{C}$ em todas as condições dos tratamentos térmicos. Esse comportamento pode ser relacionado ao fato de que a temperatura de aquecimento na têmpera de $1200^{\circ} \mathrm{C}$ foi suficientemente elevada para que uma grande (ou ao menos maior) quantidade de carbonetos dissolvessem e, em consequência, átomos de carbono e de elementos de liga entrassem em solução. Ao entrar em solução, os elementos de liga elevaram a temperabilidade do material, facilitando a transformação martensítica. O carbono, por sua vez, além de elevar a temperabilidade, ao estar em maior quantidade na austenita, gerou uma martensita de maior teor de carbono, levando a uma maior distorção da rede cristalina e resultando em plaquetas de maior dureza [1,2].

Nessas amostras também é observada a ocorrência do fenômeno de endurecimento secundário, com pico de endurecimento em $575^{\circ} \mathrm{C}$. À medida em que se eleva a temperatura de revenimento, mais energia é fornecida para que os átomos de 
carbono e elementos de liga em solução sólida precipitem na forma de carbonetos extremamente duros, além de finamente dispersos. Além disso, a precipitação dos carbonetos e a consequente diminuição da distorção da estrutura cristalina do material possivelmente levou à austenita retida tornar-se ainda menos estável, o que promoveu a transformação desta em martensita no resfriamento do revenimento [3]. Logo, acredita-se que o endurecimento da estrutura se deu pela precipitação de carbonetos ultraduros e a formação de nova martensita. No entanto, à temperatura de revenimento de $600^{\circ} \mathrm{C}$, nota-se uma diminuição da dureza. Essa redução na dureza subsequente ao pico do endurecimento secundário é associada na literatura à ocorrência de coalescimento dos carbonetos, que gradualmente se tornam cada vez menos finos e dispersos de forma homogênea [2,9].

Na figura 2 são mostradas as imagens de microestrutura do aço AISI M2 temperado a $1000^{\circ} \mathrm{C}$ e $1200^{\circ} \mathrm{C}$. Nota-se que para as duas temperaturas de aquecimento na têmpera, a estrutura formada é constituída de uma matriz martensítica e carbonetos, dos quais dois tipos podem ser observados, $\mathrm{MC}$ e $\mathrm{M}_{23} \mathrm{C}_{6}$, identificados de acordo com comparação com a literatura, a partir da morfologia e localização na microestrutura [12]. A designação $M C$ é, em geral, utilizada para representar o carboneto de vanádio, de fórmula $\mathrm{V}_{8} \mathrm{C}_{7}$, embora a substituição do vanádio por átomos de cromo e molibdênio possa ser alta nesse tipo de composto. $O$ carboneto do tipo $\mathrm{M}_{23} \mathrm{C}_{6}$ é relacionado na literatura a um dos tipos de carboneto de cromo $[7,12]$. Nota-se ainda que a estrutura temperada a $1000^{\circ} \mathrm{C}$ apresenta maior quantidade de carbonetos, uma vez que, como mencionado anteriormente e de acordo com os resultados de dureza obtidos, essa temperatura foi insuficiente para fazer com que grande quantidade desses precipitados dissolvessem e carbono e elementos de liga entrassem em solução.
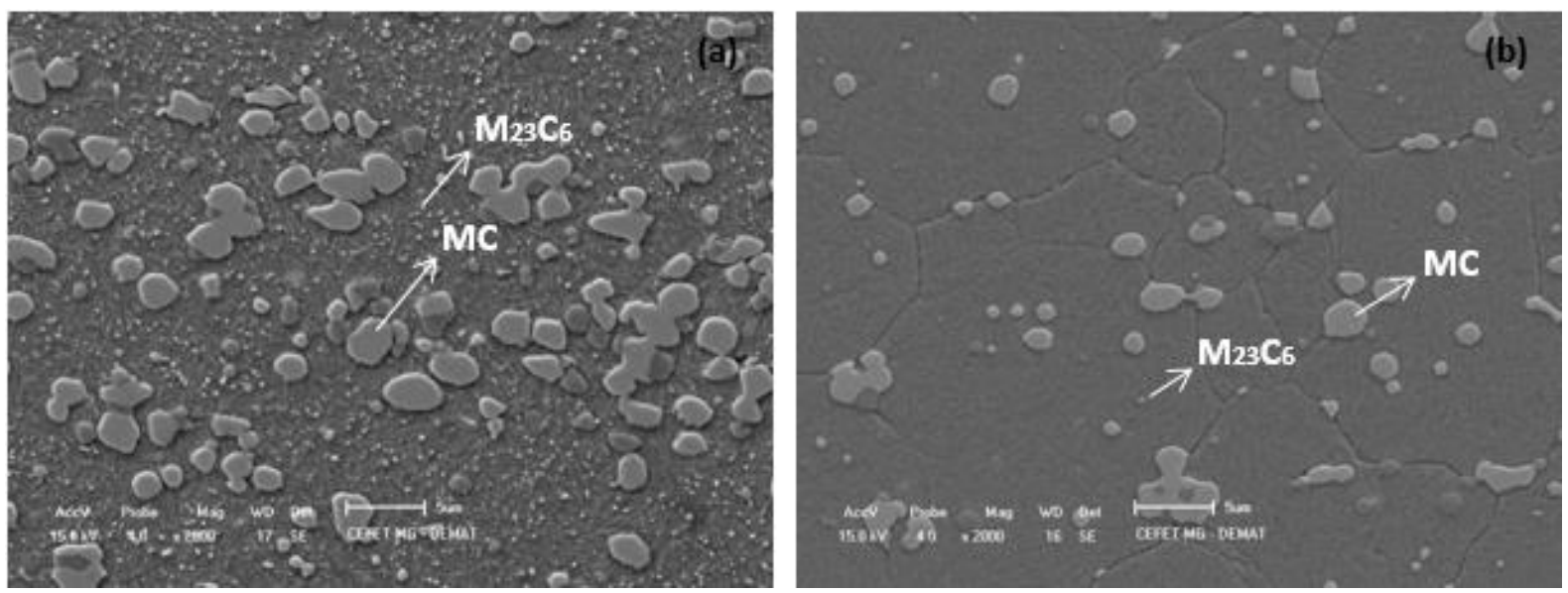

Figura 2. Fotomicrografias (MEV) do aço AISI M2 temperado a $1000^{\circ} \mathrm{C}$ (a) e $1200^{\circ} \mathrm{C}$ (b).

As imagens da microestrutura das amostras temperadas a $1000^{\circ} \mathrm{C}$ e revenidas a temperaturas distintas são mostradas na Figura 3. Observa-se a presença de matriz martensítica e grande quantidade de carbonetos, sendo esses os mesmos mostrados na figura anterior. Não foram percebidas alterações acentuadas tanto com a realização do revenimento como com o aumento da temperatura deste.

$\mathrm{Na}$ Figura 4 são mostradas as fotomicrografias para amostras temperadas a $1200^{\circ} \mathrm{C}$ e revenidas às mesmas temperaturas distintas. Nota-se grande quantidade de martensita revenida e os mesmos carbonetos do tipo $\mathrm{MC}$ e $\mathrm{M}_{23} \mathrm{C}_{6}$. Para todas as temperaturas é possível observar a menor presença de carbonetos do que para amostras temperadas a $1000^{\circ} \mathrm{C}$. Nota-se que carbonetos tipo MC estão localizados 
nos contornos e centros dos grãos e os carbonetos do tipo $\mathrm{M}_{23} \mathrm{C}_{6}$ estão distribuídos pela matriz martensítica de acordo com o que é encontrado na literatura [12].
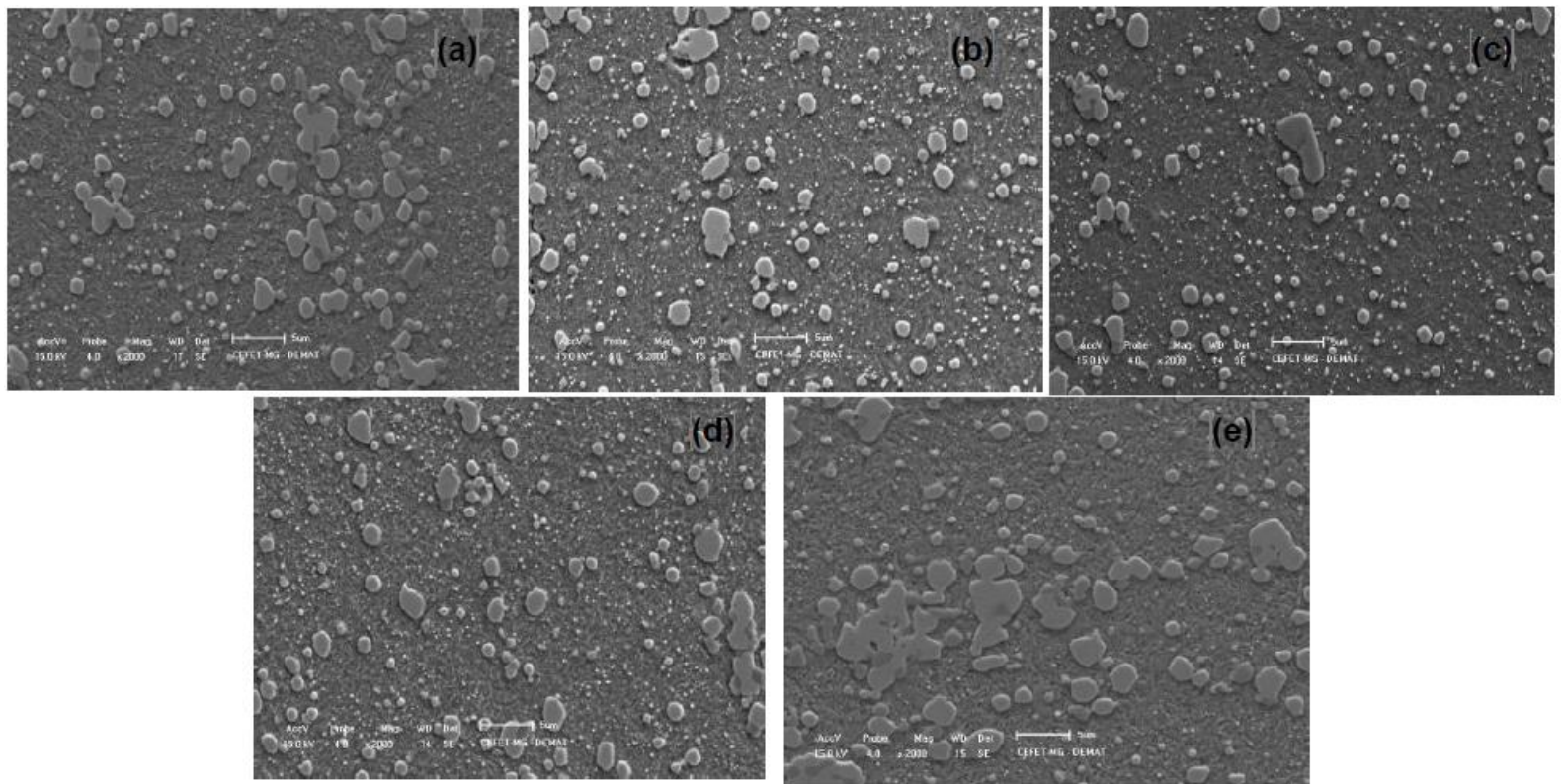

Figura 3. Fotomicrografias (MEV) do aço AISI M2 temperado a $1000^{\circ} \mathrm{C}$ e revenido a $500^{\circ} \mathrm{C}(\mathrm{a}), 525^{\circ} \mathrm{C}$ (b), $550^{\circ} \mathrm{C}$ (c), $575^{\circ} \mathrm{C}$ (d) e $600^{\circ} \mathrm{C}(\mathrm{e})$.
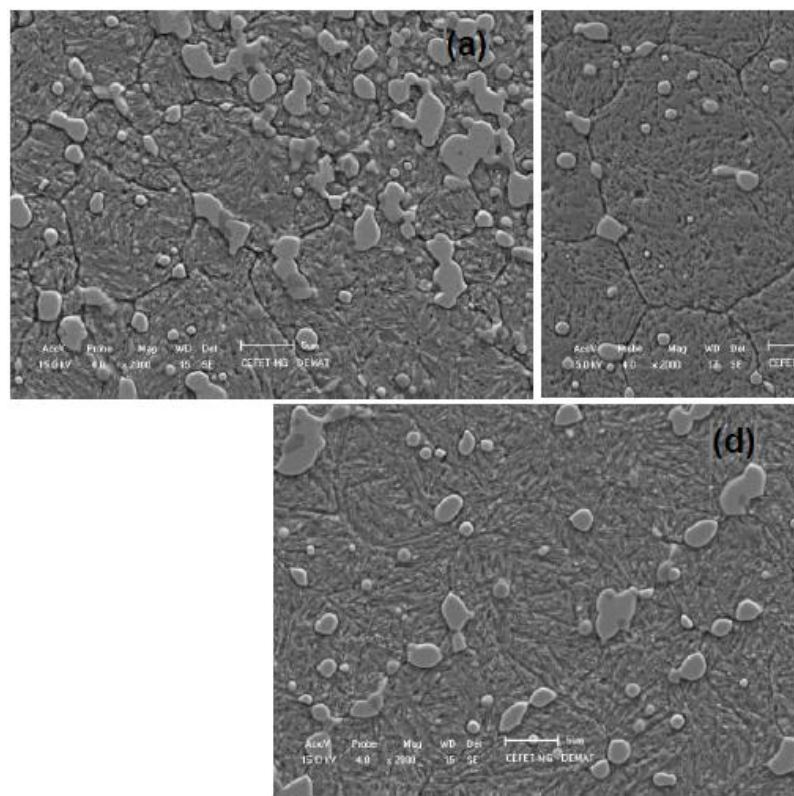

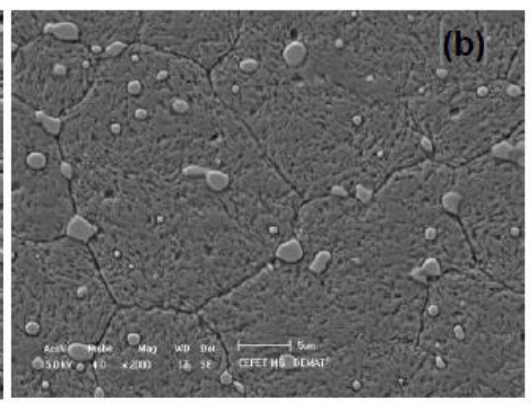

(d)

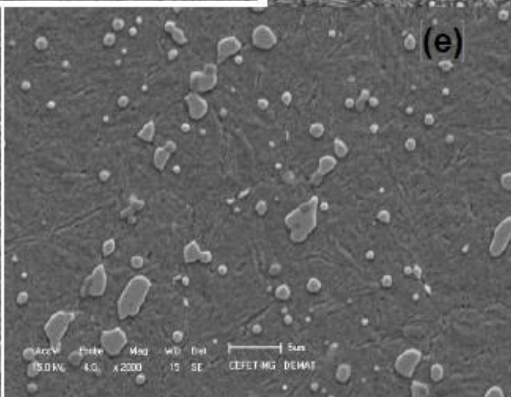

Figura 4. Fotomicrografias (MEV) do aço AISI M2 temperado a $1200^{\circ} \mathrm{C}$ e revenido a $500^{\circ} \mathrm{C}$ (a), $525^{\circ} \mathrm{C}$ (b), $550^{\circ} \mathrm{C}(\mathrm{c}), 575^{\circ} \mathrm{C}$ (d) e $600^{\circ} \mathrm{C}(\mathrm{e})$.

Na Figura 5 são apresentados os difratogramas das amostras temperadas a $1000^{\circ} \mathrm{C}$ e $1200^{\circ}$, sem revenimento. A identificação dos picos foi realizada a partir da comparação dos resultados com trabalhos encontrados na literatura $[4,13,14]$ e os padrões das fases martensita e austenita. Para as duas condições observa-se a presença de martensita $(M)$, austenita retida $(A)$ e carbonetos $(C)$. Com base nos difratogramas, de forma qualitativa, observa-se que a amostra temperada a $1200^{\circ} \mathrm{C}$ parece apresentar menor quantidade de carbonetos, uma vez que, em concordância com o que foi discutido para os resultados de dureza e as imagens de microestrutura, o aquecimento a $1200^{\circ} \mathrm{C}$ promoveu maior dissolução de carbonetos 
do que na outra condição. Em relação aos carbonetos, de acordo com a literatura, são observados picos característicos dos seguintes precipitados: $\mathrm{MC}$ e $\mathrm{M}_{6} \mathrm{C}$. Carbonetos do tipo $\mathrm{M}_{6} \mathrm{C}$ representam carbonetos de tungstênio e molibdênio e são encontrados em áreas de forte resfriamento [12].
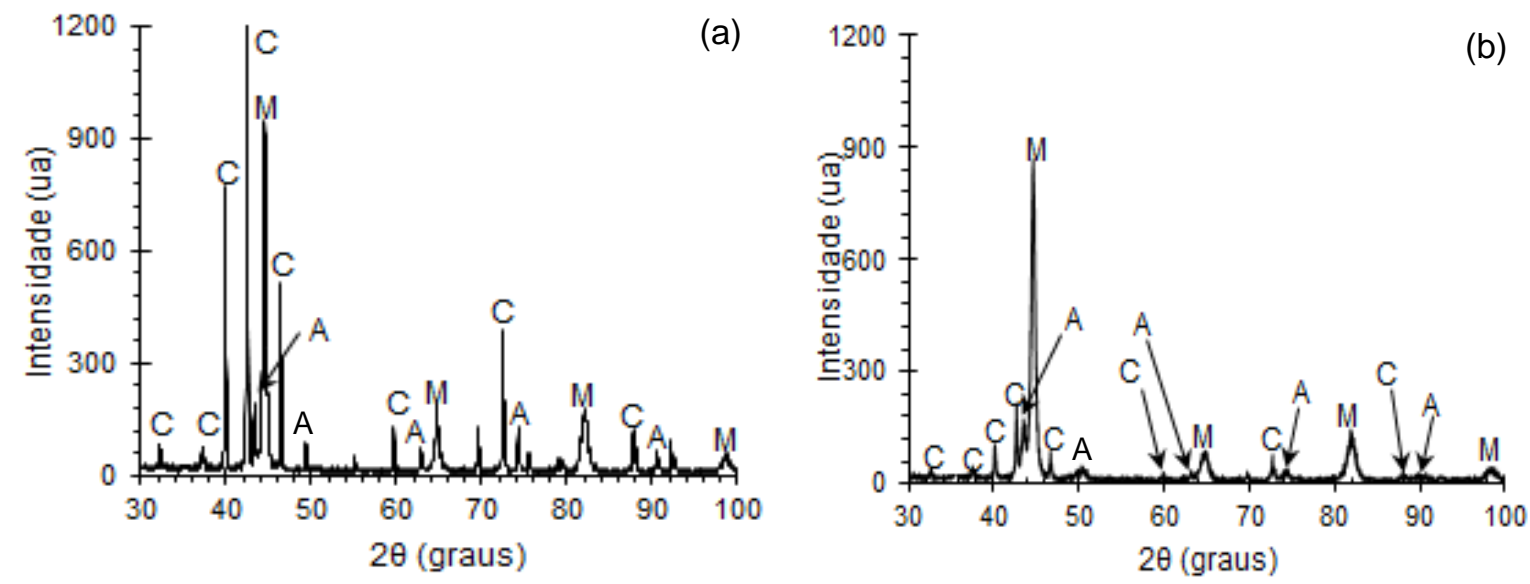

Figura 5. Difratogramas do aço AISI M2 após têmpera a $1000^{\circ} \mathrm{C}$ (a) e $1200^{\circ} \mathrm{C}$ (b)

\section{CONCLUSÃO}

Em relação a dureza do aço rápido AISI M2, conclui-se que esta, de maneira geral, aumentou com a elevação da temperatura de aquecimento na têmpera. As amostras temperadas a $1000^{\circ} \mathrm{C}$ mantiveram dureza praticamente constante independente da realização do revenimento e da temperatura deste. $O$ aumento das temperaturas de revenimento apenas surtiu efeito, causando endurecimento secundário, nas amostras temperadas à $1200^{\circ} \mathrm{C}$, em que o pico de endurecimento foi observado à temperatura de $575^{\circ} \mathrm{C}$. Em relação à microestrutura, foi observado que o material temperado a $1200^{\circ} \mathrm{C}$ apresentou menor quantidade de carbonetos. Os difratogramas corroboraram com as análises realizadas por meio das imagens de microestrutura, evidenciando ainda a presença de austenita retida.

\section{Agradecimentos}

Os autores agradecem à FINEP pelo apoio financeiro à Instituição e ao Departamento de Engenharia de Materiais do CEFET-MG pelo uso da infraestrutura.

\section{REFERÊNCIAS}

1 Chiaverini V. Aços e ferros fundidos. 7 ed. São Paulo: Associação Brasileira de Metalurgia e Materiais - ABM, 1996.

2 Silva ALVC, Mei PR. Aços e ligas especiais. 3 ed. São Paulo: Edgard Blücher, 2010.

3 Coutinho CB. Materiais metálicos para engenharia. Belo Horizonte: UFMG: Fundação Christiano Ottoni, 1992.

4 Moon HK, Lee KB, Kwon $\mathrm{H}$. Influences of $\mathrm{Co}$ addition and austenitizing temperature on secondary hardening and impact fracture behavior in $\mathrm{P} / \mathrm{M}$ high speed steels of $\mathrm{W}-\mathrm{Mo}-\mathrm{Cr}-\mathrm{V}(-\mathrm{Co})$ system. Materials Science and Engineering. 2008;474:328-334. 
5 Pan FS, Wang WQ, Tang AT, Wu LZ, Liu TT, Cheng RJ. Phase transformation refinement of coarse primary carbides in M2 high speed steel. Progress in Natural Science: Materials International. 2011;21:180-186.

6 Zhou XF, Fang F, Li F, Jiang JQ. Morphology and microstructure of M2C carbide formed at different cooling rates in AISI M2 high speed steel. J Mater Sci. 2010;46(5):1196-1202.

7 Serna MM, Rossi JL. MC complex carbide in AISI M2 high speed steel. Materials Letters. 2009;63:691-693.

8 Souza SA. Composição química dos aços. São Paulo: Edgard Blucher, 1989.

9 Totten GE. Steel Heat Treatment: metalurgy and technologies. 2 ed. Portland: Portland University, 2007.

10 Schmolz, Bickenback. Rapidur 3343. Catálogo do Fabricante. Disponível em: <http://www.schmolz-bickenbach.com.br/fileadmin/files/schmolzbickenbach.com .br/documents/Fichas_Tecnicas_novo_formato_dez2011/Acos_rapidos/Rapidur 3343.pdf>. Acesso em: 20 nov. 2015.

11 ASM Handbook. Heat treating. Ohio: ASM International, 2002.

12 Vitry V, Nardone S, Breyer JP, Sinnaeve M, Delaunois F. Microstructure of two centrifugal cast high speed steels for hot strip mills applications. Materials \& Design. 2011;34:372-378.

13 Akbari A, Mohammadzadeh R, Templier C, Riviere JP. Effect of the initial microstructure on the plasma nitriding behavior of AISI M2 high speed steel. Surface and Coatings Technology. 2010;204(24):4114-4120.

14 Dobrzanski LA, Matula G, Várez A, Levenfeld B, Torralba JM. Fabrication methods and heat treatment conditions effect on tribological properties of high speed steels. Journal of Materials Processing Technology. 2014;157:324-330. 